\title{
Assessment of Residual Plastic Strain Using Enhanced Crystallographic Contrast
}

Jian Li

Materials Technology Laboratory, CANMET, 568 Booth St. Ottawa, Ontario, Canada, K1A 0G1

The detection and evaluation of residual plastic deformation in microscopic scale is important in understanding materials performance under many circumstances. For example, in a wear test, the formation of a subsurface deformation zone is closely related to the wear regime and ultimately affects its wear resistance. Characteristics of small plastic zones ahead of stress corrosion crack (SCC) tips are important to determine the activities of the cracks. However, assessment of these very small-scale plastic deformation zones could be challenging. The conventional optical microscope and scanning-electron microscope (SEM) do not provide crystallographic contrast with sufficient sensitivity. Site-specific transmission-electron microscope (TEM) analyses are usually difficult due to the limited size of the analysis area and the problems in sample preparation.

Since its development in the mid 1980s, the focused-ion beam (FIB) microscope has been used extensively in the semiconductor industry. With the increased imaging resolution in recent years, FIB microscopes have been widely used in materials characterization, e.g. site-specific TEM specimen preparation and stress-free cross sectioning using the primary gallium ion beam. The FIB secondary electron (SE) images are extremely sensitive to crystallographic orientation. Grains with misorientations as small as $2^{\circ}$ could show distinctly different contrasts. Figure 1 shows a series of FIB SE images of a low-carbon steel sample taken from the same location with different tilt angles. The high sensitivity to the crystallographic orientation of individual grains is due to the high sensitivity of the gallium ion channeling into the substrate. Using this extremely sensitive characteristic of FIB SE imaging, residual plastic strain can be detected. The dislocations in the deformed matrix are not usually distributed randomly in the deformed matrix. They usually form cell boundaries in sub-micrometer scale [2]. These small cells can be regarded as subgrains (or at least the origin of subgrains). The variations in crystallographic orientation among the small cells are usually cumulative and related to the local strain tensor. However, within a single mother grain, variation in crystallographic orientation could be very small and not detectable by either optical microscope or SEM.

Figure 2a shows a typical SEM image taken from a polished cross section of an aluminum alloy subjected to dry sliding wear. The FIB SE image (Figure 2b) taken from a similar area shows the formation of very fine subgrains beneath the worn surface. This fine-grained structure has significant implications in the wear behavior of this material [3]. Figure 3 shows optical, SEM and FIB images taken from the same SCC tip. Deformed substrate near the crack tip can be seen clearly in the FIB SE image. The existence of this plastic zone is of paramount importance to the activity of the SCC.

\section{REFERENCES}

[1]. Office of Pipeline Safety, "SCC Threat Advisory Notice", October 2003.

[2]. M.A. Brown, Journal of Inst. Of Metals, 1952, 80, 115-124.

[3]. Jian Li, M. Elmadagi, V.Y. Guertsman, J. Lo and A.T. Alpas, Materials Science and 
Engineering, 2006, in press.

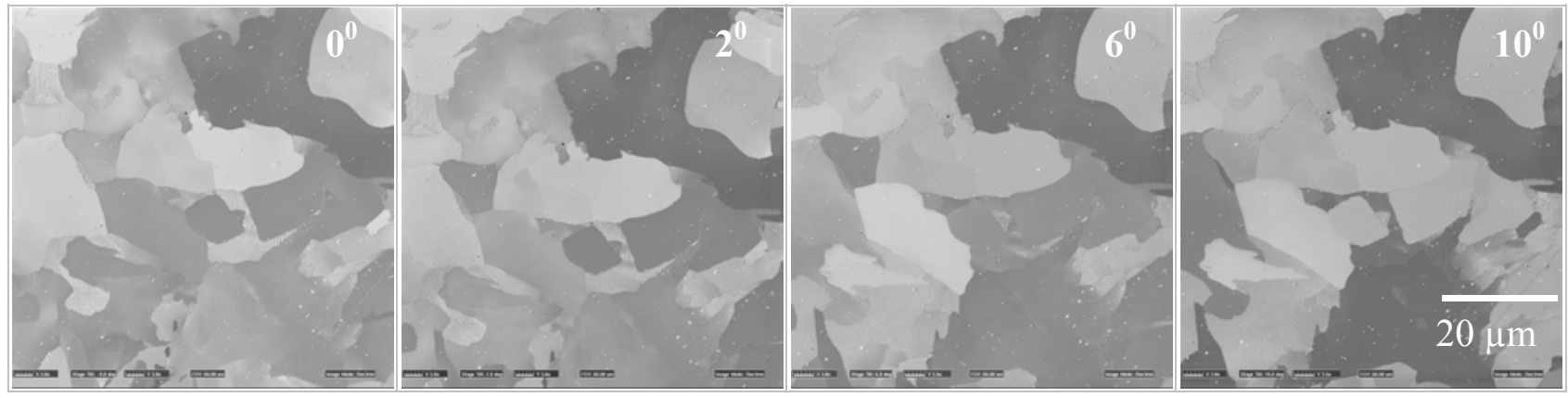

Figure 1. FIB SE images of an area on a metallurgically polished low-carbon steel surface with various sample tilt angles.
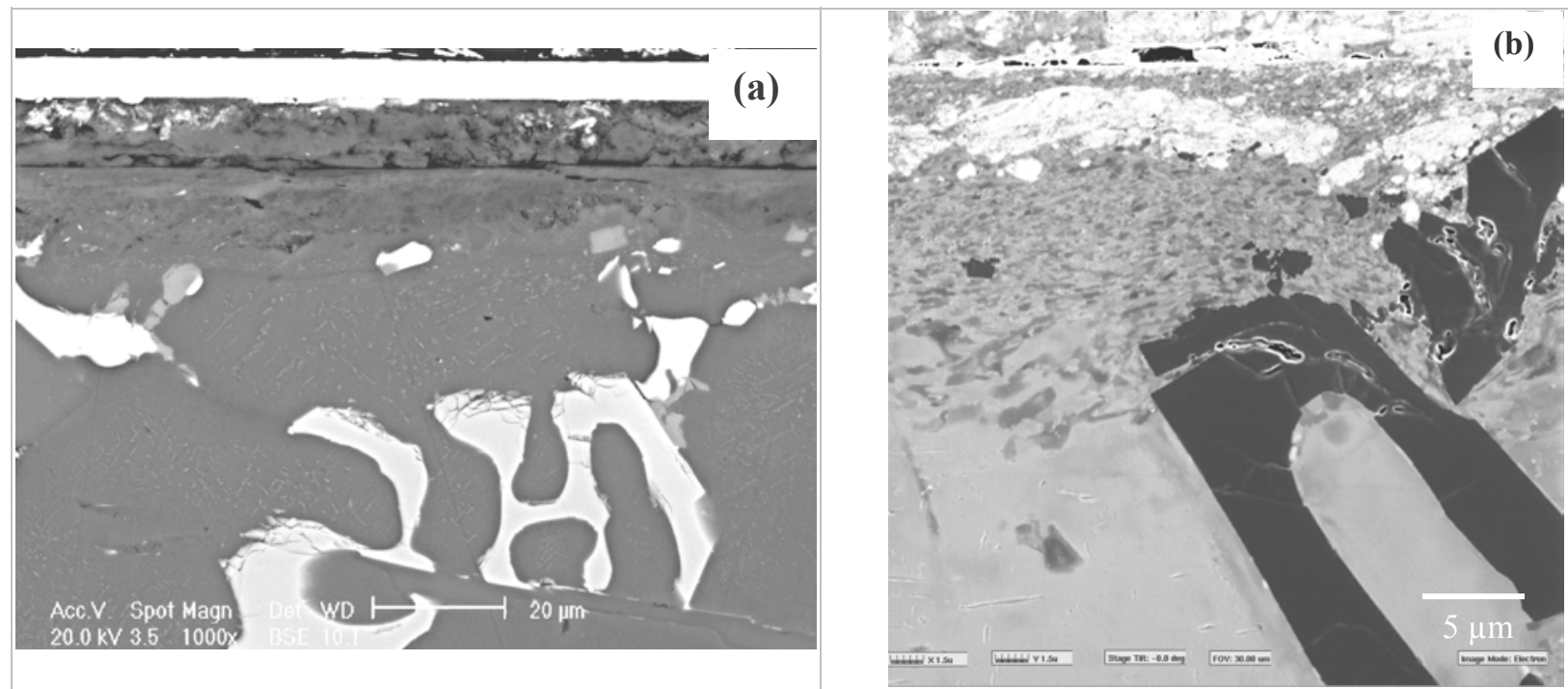

Figure 2. SEM and FIB images of the polished cross-section of an aluminum alloy subjected to dry sliding wear. (a) SEM backscattered electron image, (b) FIB SE image showing the subsurface deformation zone.

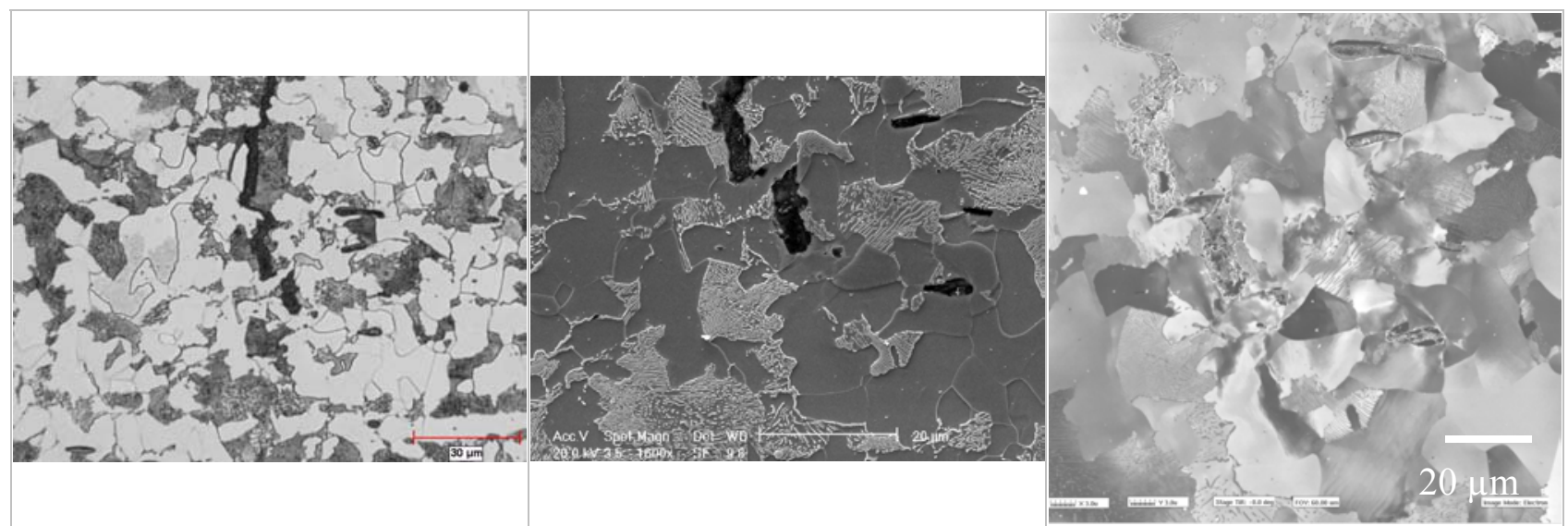

Figure 3. Comparison of optical, SEM and FIB images on a stress corrosion crack tip. (a) Optical image, (b) SEM image, (c) FIB SE image on as-polished surface. 